\title{
Sistem Kontrol Injeksi Arus pada Inverter Berbasis Metode Proportional Integral
}

\author{
Eko Wirahadi Saputra, Hermawan, Iwan Setiawan* \\ Departemen Teknik Elektro Fakultas Teknik, Universitas Diponegoro, \\ Jl. Prof. Soedarto, SH, Kampus UNDIP Tembalang, Semarang, Indonesia 50275
}

\begin{abstract}
Abstrak
Saat ini energi terbarukan yang bersumber dari energi hijau terus dikembangkan dan dioptimalkan. Khusus pemanfaatan energi terbarukan dengan keluaran daya DC, maka secara praktis diperlukan sistem inverter agar bisa digunakan sebagai pengganti sumber energi daya AC. Agar bekerja secara optimal, secara internal dalam sebuah sistem inverter sumber tegangan, perlu dilengkapi sistem umpan balik arus. Salah satu metode pengontrolan arus inverter yang relative popular adalah metode kontrol ProporsionalIntegral. Dalam penelitan ini, dirancang inverter satu fasa tipe Full Bridge dengan metode kontrol proportional-integral menggunakan mikrokontroler 16-bit dsPIC30F4011. Dengan sensor arus ACS71205B arus keluaran inverter diumpan-balikkan. Pengujian dilakukan dengan variasi beban $8 \Omega$ dan $10 \Omega$, dengan memvariasikan sejumlah nilai parameter $\mathrm{kp}$ dan $\mathrm{ki}$. Berdasarkan hasil pengujian metode proportional integral untuk pengontrollan arus pada inverter satu fasa memiliki respon sistem cepat dan relative stabil.
\end{abstract}

Kata kunci: inverter; kontrol arus; proportional integral; dsPIC30F4011; ACS712-05

\begin{abstract}
[Title: Currents injection control system on inverter using proportional-integral method] Currently, renewable energy from green energy sources continues to be developed and optimized. Specifically, for the renewable energy utilization with a DC power output, an inverter system is practically required so that it can be used as a substitute for the AC power energy sources. In order to work optimally, internally in the voltage source inverter system, a current feedback system is required. One of the relatively popular inverter current control methods is the Proportional-Integral control method. In this research, a Full Bridge type single phase inverter was designed with a proportional-integral control method using a 16-bit dsPIC30F4011 microcontroller. With current sensor ACS712-05B inverter output current is fed back. The test is carried out with a load variation of $8 \Omega$ and $10 \Omega$, by varying the parameter values of $k p$ and $k i$. Based on the test results of the proportional integral method for current control in single-phase inverters, the system response is fast and relatively stable.
\end{abstract}

Keywords: inverter; current control; proportional integral; dsPIC30F4011; ACS712-05

\section{Pendahuluan}

Energi terbarukan terus dikembangkan dan dioptimalkan dengan mengubah pola pikir bahwa energi terbarukan bukan sekedar sebagai energi alternatif dari bahan fosil yang merupakan sumber daya yang tidak dapat diperbarui sehingga lambat laun akan habis, tetapi harus menjadi pasokan energi nasional dengan porsi energi baru terbarukan sebesar $23 \%$ pada tahun 2025 dan

\footnotetext{
${ }^{*}$ Penulis Korespondensi.

E-mail: iwansetiawan@live.undip.ac.id
}

di tahun 2050 paling sedikit sebesar 31\% (PP No.79/2014 tentang Kebijakan Energi Nasional) (Dewan Energi Nasional, 2016). Sumber energi terbarukan yang terhubung ke sistem tenaga listrik meningkat secara signifikan, diantaranya pemanfaatan energi terbarukan yang dari angin, mikrohidro, dan solar energi (Selvaraj $d k k$., 2008; Setiawan $d k k$., 2018; Kuspranoto $d k k$., 2018). Dalam pemanfaatan energi terbarukan yang sebagian besar menghasilkan tegangan DC, maka dibutuhkan inverter agar bisa digunakan sebagai pengganti sumber energi dari PLN (tegangan AC 220v 50Hz). Tingkat 


\section{TEKNIK, 41 (2), 2020, 187}

konsumsi energi untuk peralatan elektronik tidak sama, maka diperlukan pengontrol arus keluaran inverter satu fasa.

Berdasarkan metode kontrol yang digunakan, ada sejumlah strategi yang relative popular dalam sistem control umpan balik arus inverter satu phase, yaitu diantaranya: Sistem Kontrol Hysteris (Rahim $d k k$., 2007; Dahono, 2009), Sistem Kontrol Proporsional-Resonant (Zhou $d k k ., 2010$; Kuperman, 2015) dan sistem kontrol proporsional integral (Ciobotaru $d k k$., 2006)

Penggunaan sistem inverter dalam kondisi beban nonlinear berpengaruh terhadap kualitas daya dalam sistem tenaga. Perilaku nonlinier dari inverter dan beban nonlinier menyebabkan tegangan dan arus sistem menjadi harmonik yang kemudian menyebabkan kerusakan sistem daya keseluruhan. Oleh karena itu, penerapan standar IEEE 519-1992 dan standar IEC yang mengatur kompatibilitas total harmonic distortion (THD) dalam sistem tenaga sangat penting (Ajot $d k k$., 2017).

Tujuan penelitian ini adalah merancang dan merealisasikan sistem control arus pada inverter satu fasa tipe Full Bridge dengan metode kontrol proportionalintegral menggunakan mikrokontroler 16-bit dsPIC30F4011. Dengan sensor arus ACS712-05B arus keluaran inverter diumpan-balikkan. Pengujian dilakukan dengan variasi beban $8 \Omega$ dan $10 \Omega$, dan beberapa nilai parameter kp dan ki.

\section{Bahan dan Metode}

Inverter satu fasa tipe full bridge dengan kontrol arus proportional integral terdiri dari blok DC Link, blok rangkaian kontrol, blok sensor arus ACS712-05B, blok modul Digital-to-Analog Converter AD7302, serta blok beban. Gambar 1 dan Gambar 2 berturut-turut memperlihatkan blok diagram rangkaian inverter satu phase dan prototipe rangkaian pengujiannya.

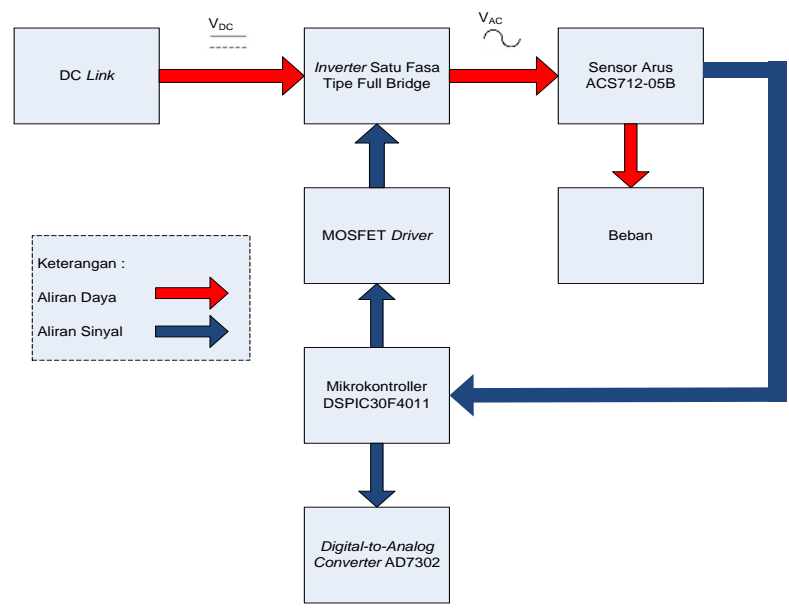

Gambar 1. Diagram Blok Perancangan Inverter Satu Fasa
Inverter satu fasa mendapatkan sumber tegangan DC dari DC link yang akan diproses melalui pensaklaran pada MOSFET driver menggunakan switching frequency of the unipolar SPWM modulation dari perintah mikrokontroller DSPIC30F4011. Proses pensaklaran itu sendiri dihasilkan dari sinyal kontrol proportional integral berdasarkan arus aktual yang diukur modul sensor dan arus referensi. Arus aktual diperoleh mikrokontroller DSPIC30F4011 melalui modul sensor arus ACS712-05B menggunakan analog digital converter (ADC), sedangkan arus referensi diperoleh dari pembangkitan sinyal sinus pada mikrokontroller yang amplitudonya dapat diatur menggunakan potensiometer. Hasil arus referensi dan arus aktual akan direpresentasikan ke modul Digital To Analog (DAC) oleh mikrokontroller DSPIC30F4011. Keluaran inverter satu fasa dihubungkan dengan beban yang akan membantu proses analisa dan pengujian inverter. Pada penelitian perancangan inverter satu fasa blok DC link menggunakan full-wave bridge rectifier dengan sumber satu fasa, sedangkan blok rangkaian kontrol terdiri dari mikrokontroler 16-bit DSPIC30F4011 dan MOSFET driver.

\subsection{MOSFET Driver}

Rangkaian TLP250 digunakan untuk mengisolasi dan menguatkan sinyal kontrol Proportional Integral dengan level tegangan 5 Volt yang dibangkitkan oleh mikrokontroller DSPIC30F4011 menjadi level tegangan yang lebih tinggi dengan sistem ground terpisah (level tegangan 15 Volt) dan cukup untuk memicu MOSFET (Metal Oxide Semiconductor Field Effect Transistor) sebagai driver (Hart, 2011). Gambar 3 memperlihatkan rangkaian driver yang digunakan untuk menggerakan Mosfet pada rangkaian.

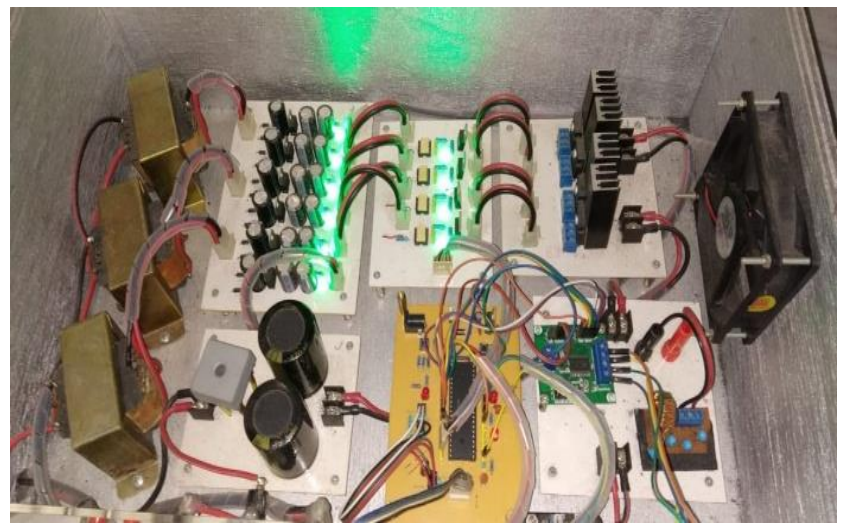

Gambar 2. Inverter satu fasa tipe full bridge dengan kontrol arus proportional integral. 


\section{TEKNIK, 41 (2), 2020, 188}

MOSFET 1 (high-side) terhubung dengan optocoupler yang memiliki suplai DC terpisah dengan fasa lain dan MOSFET Driver sisi low, sedangkan MOSFET 2 (low-side) terhubung dengan rangkaian optocoupler yang memiliki titik referensi ground yang sama dengan MOSFET Driver sisi low pada fasa yang lain (Hart, 2011).

\subsection{Sensor Arus ACS712-05B}

Sensor arus ACS712-05B digunakan untuk mengukur dan membaca nilai arus aktual yang melalui beban. Sensor ini bekerja dengan prinsip hall effect. Arus yang mengalir melewati sensor akan dibaca dan dikonversikan menjadi nilai tegangan yang proporsional, kemudian sinyal berupa tegangan tersebut akan dibaca oleh modul $A D C$ pada mikrokontroler DSPIC30F4011.

Tegangan keluaran sensor akan bernilai sekitar 2,5 $\mathrm{V}$ saat tidak ada arus yang mengalir melewati sensor. Berdasarkan datasheet, sensitivitas sensor arus ACS71205B ini adalah sebesar $185 \mathrm{mV} / \mathrm{A}$ (Zhang dkk., 2014), sensor yang digunakan tersebut sudah dilengkapi IC opamp atau penguat sinyal TLC2272ACD yang dapat digunakan untuk mengatur nilai offset dan gain melalui dua potensiometer. Potensiometer gain diatur hingga nilai sensitivitas sensor berubah menjadi $0,5 \mathrm{~V} / \mathrm{A}$, sehingga nilai tegangan keluaran maksimal dari sensor saat arus yang terbaca sebesar 5 A sesuai dengan Persamaan 1.

$$
\begin{aligned}
& V_{\text {out }}=2,5+0,5 \cdot i \\
& V_{\text {out }}=2,5+0,5 \cdot 5 \\
& V_{\text {out }}=5 \mathrm{~V}
\end{aligned}
$$

Tegangan keluaran sensor diatur menjadi maksimal $5 \mathrm{~V}$ untuk memudahkan pembacaan oleh modul analog-to-digital converter yang memiliki tegangan referensi sebesar $5 \mathrm{~V}$.

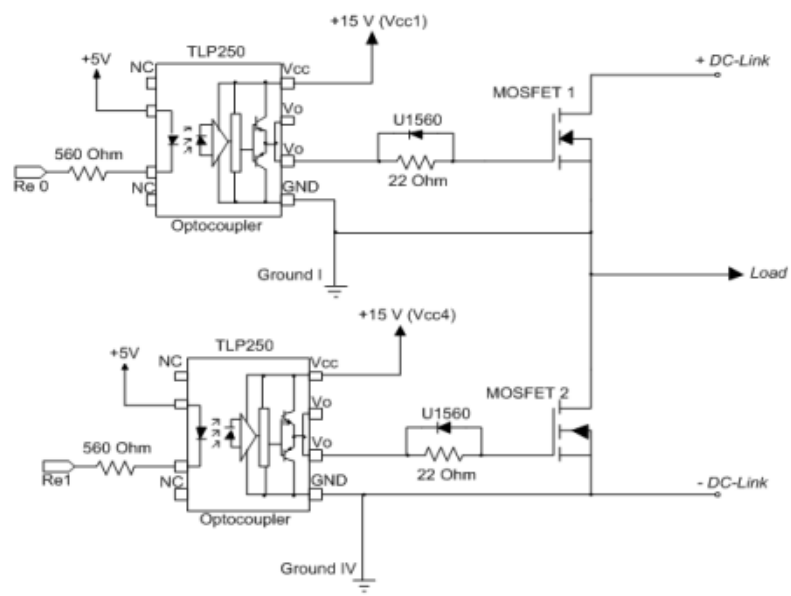

Gambar 3. Rangkaian MOSFET Driver TLP250

\subsection{Kontroler Arus Proportional-Integral}

Kontrol Proportional Integral digunakan untuk mengumpan balikkan nilai keluaran arus dari inverter dengan memberikan gain. Nilai error $e(t)$ diperoleh dari hasil pengurangan nilai arus aktual yang diukur oleh sensor arus (iact) dan nilai referensi arus yang diberikan lewat potensiometer (iref) (Pradana $d k k$., 2011). Blok diagram sistem control Proportional Integral pada pengontrolan arus ini dapat dilihat pada Gambar 4. Setelah nilai $(t)$ didapatkan, kontroler akan menghitung nilai error dengan nilai penguatan untuk menghasilkan sinyal kontrol.

Persamaan 2 menunjukkan persamaan kontroler proportional-integral dalam bentuk Transformasi Laplace.

$$
H(s)=K P\left(1+\frac{1}{\text { Tis }}\right)
$$

Parameter yang dibutuhkan untuk kontroler PI adalah (1) $K_{p}$ untuk mendapatkan respon transient yang cepat dan kestabilan yang bagus dan (2) $K_{i}$ untuk mengurangi steady-state error.

Nilai parameter $K_{\mathrm{p}}$ dan $K_{\mathrm{f}}$ ditentukan dengan proses tuning pada simulasi system inverter satu fasa pada MATLAB. Proses tunning dilakukan untuk menuntukan parameter terbaik pada metode proportional Integral. Fitur yang digunakan dalam proses tunning pada MATLAB yaitu LINEAR ANALYSIS dengan menggunakan bode plot. Gambar 5 dan Gambar 6 berikut berturut-turut memperlihatkan diagram bode pengaruh perubahan $\mathrm{Kp}$ dan perubahan $\mathrm{Ki}$ dalam kawasan frekuensi.

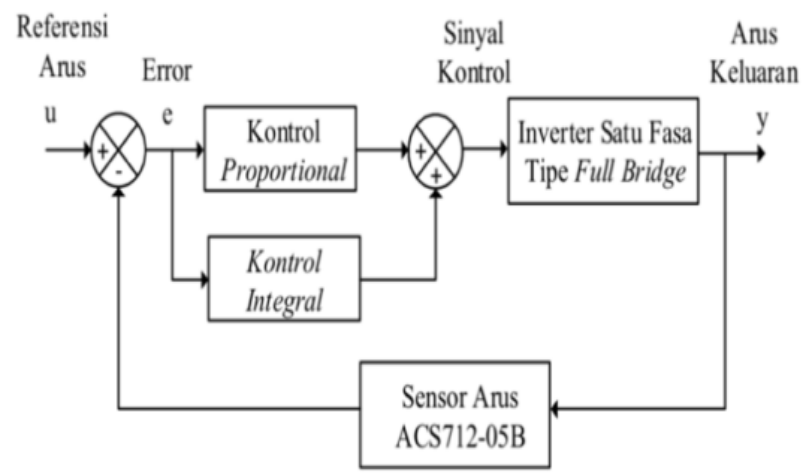

Gambar 4. Diagram Blok Kontroler ProportionalIntegral 


\section{TEKNIK, 41 (2), 2020, 189}

\section{Hasil dan Pembahasan}

Pengujian penerapan metode PI pada inverter dengan kombinasi nilai $K_{p}, K_{\mathfrak{i}}$ yang berbeda. Nilai variasi $K_{p}, K_{\mathrm{i}}$ yg digunakan pada pengujian diambil berdasarkan hasil pengamatan proses tunning pada MATLAB yaitu Linear Analysis dengan menggunakan bode plot. Arus yang diamati adalah arus referensi dan arus keluaran inverter menggunakan kontrol PI. $K_{p}$ dan $K_{f}$ akan diubah berdasarkan penguatan. $K_{p}$ lebih kecil daripada $K_{\tilde{\mathrm{I}}}$ dan $K_{p}$ lebih besar daripada $K_{\mathrm{i}}$. Pengujian ini bertujuan untuk mengetahui bentuk gelombang arus referensi dan gelombang arus yang mendapatkan pengaruh sinyal kontrol akibat variasi parameter dari proportional integral.

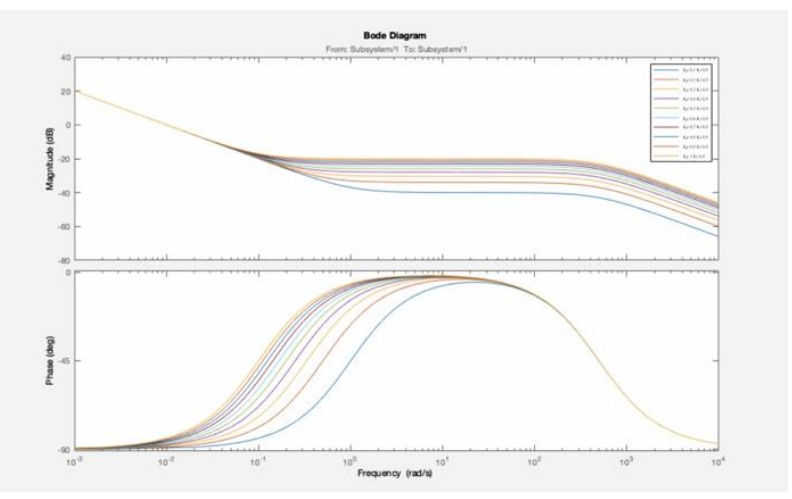

Gambar 5. Bode plot $K_{\mathrm{i}}$ tetap

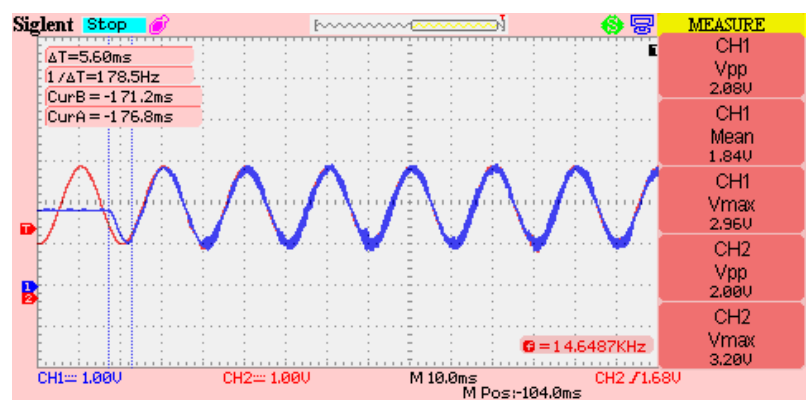

Gambar 7. Tegangan Keluaran dengan Arus Referensi $2 \mathrm{~A}$ dengan Parameter Pengukuran $\left(\boldsymbol{K}_{p}=0.4\right.$ and $\boldsymbol{K}_{\bar{i}}=$ $0.9)$
3.1. Pengujian Pada Variasi Parameter $\mathbf{K}_{\mathbf{p}}$ dengan Nilai $\mathbf{K}_{\mathbf{1}}$ Tetap (Arus referensi 2A)

Gambar 7 dan 8 berturut-turut memperlihatkan hasil pengujian untuk nilai Kp yang berbeda. Pada Gambar 7 bentuk gelombang dari arus actual (warna biru) mengikuti bentuk gelombang dari arus referensi (warna merah) dengan waktu $5.60 \mathrm{~ms}$. Pengamatan gelombang dilakukan pada $\mathrm{v} / \mathrm{div}=1 \mathrm{~V}, \mathrm{t} / \mathrm{div}=10.0 \mathrm{~ms}$, dan faktor pengali probe oscilloscope 1x. Berdasarkan hasil pengamatan melalui Oscilloscope diperoleh tegangan maksimum dan periode sebagai berikut :

$$
\begin{aligned}
& V_{D A C}=1 \text { div } \cdot 1 \mathrm{~V} / \mathrm{div} \cdot 1 \\
& V_{D A C}=1 \mathrm{volt} \\
& \Delta t=-171.1 \mathrm{~ms}-(-178.8) \mathrm{ms} \\
& t=5.60 \mathrm{~ms}
\end{aligned}
$$

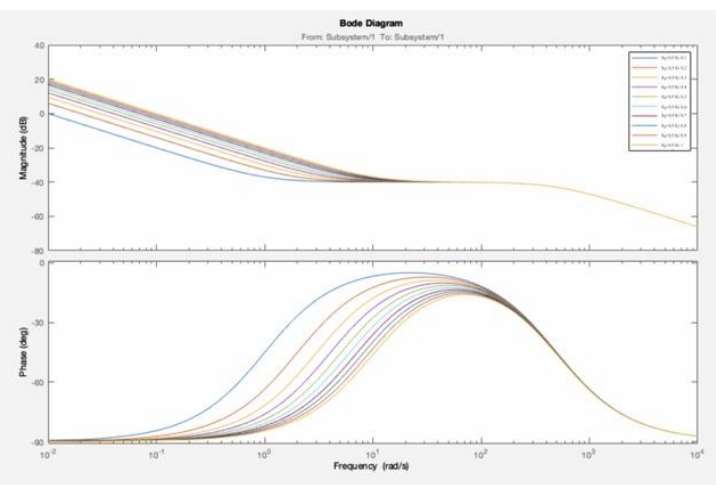

Gambar 6. Bode plot $K_{p}$ tetap

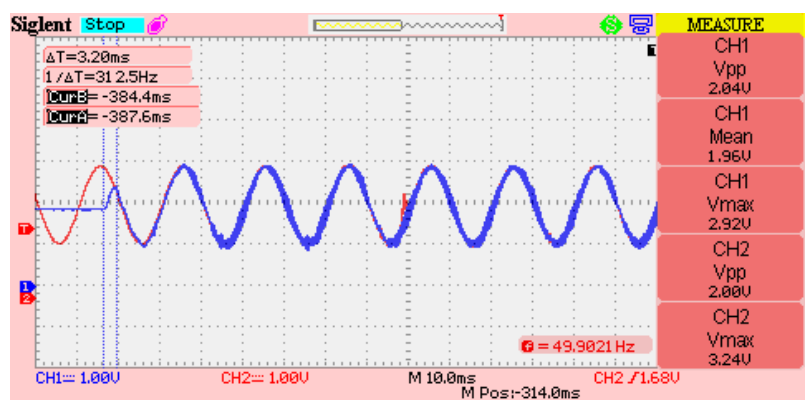

Gambar 8. Tegangan Keluaran dengan Arus Referensi $2 \mathrm{~A}$ dengan Parameter Pengukuran $\left(\boldsymbol{K}_{p}=0.7\right.$ and $\boldsymbol{K}_{\bar{i}}=$ $0.9)$ 


\section{TEKNIK, 41 (2), 2020, 190}

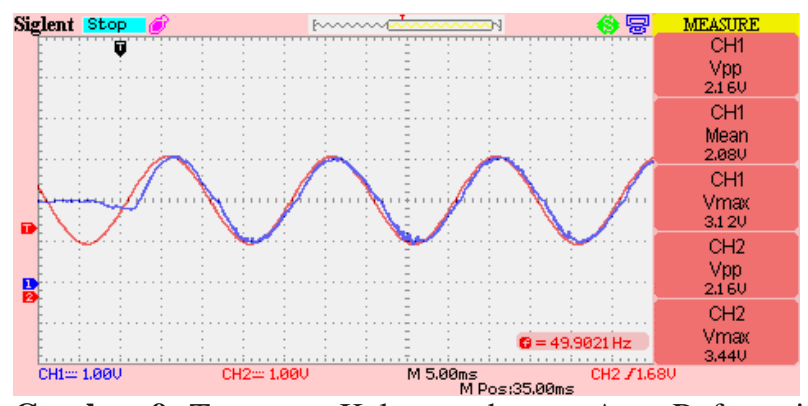

Gambar 9. Tegangan Keluaran dengan Arus Referensi 2 A dengan Parameter Pengukuran $\left(K_{p}=0.9\right.$ and $K_{i}=$ $0.3)$

Pada Gambar 8 bentuk gelombang dari arus actual (warna biru) mengikuti bentuk gelombang dari arus referensi (warna merah) dengan waktu $3.20 \mathrm{~ms}$. Pengamatan gelombang dilakukan pada $\mathrm{v} / \mathrm{div}=1 \mathrm{~V}$, $\mathrm{t} / \mathrm{div}=10.0 \mathrm{~ms}$, dan faktor pengali probe oscilloscope 1x. Berdasarkan hasil pengamatan melalui Oscilloscope diperoleh tegangan maksimum dan periode:

$$
\begin{aligned}
& V_{D A C}=1 \text { div } \cdot 1 \mathrm{~V} / \text { div } \cdot 1 \\
& V_{D A C}=1 \text { volt } \\
& \Delta t=-384.4 \mathrm{~ms}-(-387.6) \mathrm{ms} \\
& t=3.20 \mathrm{~ms}
\end{aligned}
$$

Berdasarkan hasil pengujian pada Gambar 7 dan 8. diperoleh bentuk gelombang keluaran di beban 10 ohm untuk arus referensi 2 A. Pengamatan gelombang dilakukan pada $\mathrm{v} / \mathrm{div}=1 \mathrm{~V}, \mathrm{t} / \mathrm{div}=10.0 \mathrm{~ms}$, dan faktor pengali probe oscilloscope 1x. Semakin besar Parameter $K_{p}$ mempengaruhi cepat respon sinyal dan membuat sinyal aktual lebih proportional terhadap sinyal referensi. Gelombang sinus yang terbentuk sudah membentuk gelombang sinus dengan baik

3.2. Pengujian Pada Variasi Parameter $K_{\tilde{\mathrm{i}}}$ dengan Nilai $\mathrm{K}_{\mathrm{p}}$ Tetap (Arus referensi 2A)

Hasil pengujian pengaruh perubahan Ki dengan nilai Kp yang tetap, berturut-turut diperlihatkan pada Gambar 9 dan Gambar 10. Berdasarkan hasil pengujian pada Gambar 9 dan 10 diperoleh bentuk gelombang keluaran di beban $10 \mathrm{ohm}$ untuk arus referensi $2 \mathrm{~A}$. Pengamatan gelombang dilakukan pada $\mathrm{v} / \mathrm{div}=1 \mathrm{~V}$, $\mathrm{t} / \mathrm{div}=5 \mathrm{~ms}$, dan faktor pengali probe oscilloscope $1 \mathrm{x}$. Ketika parameter $K_{r i}$ diperbesar, kesalahan steady state error menurun.

\section{Kesimpulan}

Berdasarkan hasil yang telah dicapai selama analisis, perancangan, implementasi, dan pengujian pada penelitian ini, desimpulan pengaruh parameter gain pada metode kontrol Proportional Integral terhadap arus

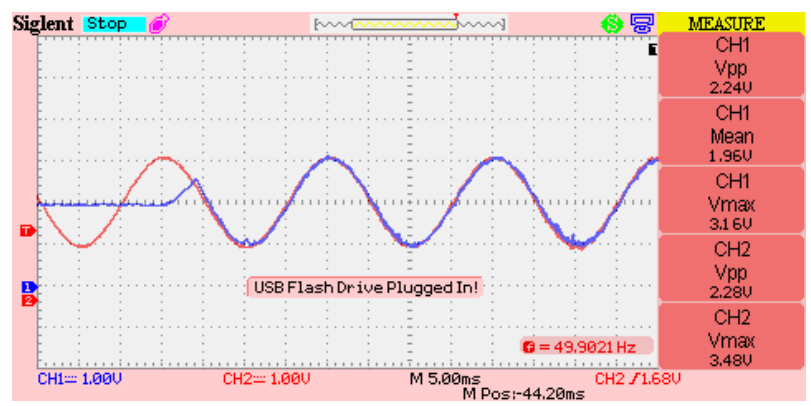

Gambar 10. Tegangan Keluaran dengan Arus Referensi 2 A dengan Parameter Pengukuran $\left(K_{p}=0.9\right.$ and $K_{i}=$ $0.8)$

keluaran inverter adalah Proportional gain $\left(\mathrm{K}_{\mathrm{p}}\right)$ untuk mempercepat respon transient serta membuat keluaran inverter lebih proportional terhadap referensi. Semakin besar $K_{p}$ akan membuat keluaran inverter lebih proportional terhadap referensi. Integral gain $\left(\mathrm{K}_{\mathfrak{i}}\right)$ untuk mengurangi steady-state error.

\section{Daftar Pustaka}

Ajot, T. C. A., Salimin, S., \& Aziz, R. (2017). Application of PI Current Controller in Single Phase Inverter System Connected to Non Linear Load. IOP Conference Series: Materials Science and Engineering, 226(1). https://doi.org/10.1088/1757-899X/226/1/012135

Ciobotaru, M., Teodorescu, R., \& Blaabjerg, F. (2006). Control of single-stage single-phase PV inverter. EPE Journal, 16(3), 20-26.

Dahono, P. A. (2009). New hysteresis current controller for single-phase full-bridge inverters. IET Power Electronics, 2(5), 585-594.

Dewan Energi Nasional (2016). Indonesia energy outlook 2016. Jakarta: Sekretariat Jenderal Dewan Energi Nasional.

Hart, Daniel W. (2011). Power Electronics. New York: McGraw-Hill.

Kuperman, A. (2015). Proportional-resonant current controllers design based on desired transient performance. IEEE Transactions on Power Electronics, 30(10), 5341-5345.

Kuspranoto, A. H., Achmad, S. J. Al, Setiawan, I., \& Facta, M. (2018). Design and Development of Injection Current Control on Inverter-Based Proportional Resonant Method. Proceedings 2018 5th International Conference on Information Technology, Computer and Electrical Engineering, ICITACEE 2018, 191-196. https://doi.org/10.1109/ICITACEE.2018.8576919

Pradana, M. I., Riyadi, M. A., \& Setiawan, I. (2018). Implementasi Kontrol Arus Pada Inverter Satu 


\section{TEKNIK, 41 (2), 2020, 191}

Fasa Menggunakan Dspic30f4011 Dengan Metode Kontrol Proportional Integral. Transient: Jurnal Ilmiah Teknik Elektro, 7(2), 529-535.

Rahim, N. A., \& Selvaraj, J. (2007, November). Implementation of hysteresis current control for single-phase grid connected inverter. In 2007 7th International Conference on Power Electronics and Drive Systems (pp. 1097-1101). IEEE.

Selvaraj, J., Rahim, N. A., \& Krismadinata, C. (2008). Digital PI current control for grid connected PV inverter. 3rd IEEE Conference on Industrial Electronics and Applications, 742-746. https://doi.org/10.1109/ICIEA.2008.4582614
Setiawan, I., Andromeda, T., Facta, M., \& Handoko, S. (2018). Implementation and Performance Analysis of a Single Phase Synchronization Technique based on T/4 Delay PLL. 8(1).

Zhang, N., Tang, H., \& Yao, C. (2014). A systematic method for designing a PR controller and active damping of the LCL filter for single-phase gridconnected PV inverters. Energies, 7(6), 39343954. https://doi.org/10.3390/en7063934

Zhou, K., Zhu, W., \& Zhu, L. (2010, September). Proportional-resonant current control of singlephase grid-tied PV inverter system. In CICED 2010 Proceedings (hal. 1-4). IEEE. 